\title{
JECH
}

\section{How political epidemiology research can address why the millennium development goals have not been achieved: developing a research agenda}

D Gil-González, M T Ruiz-Cantero and C Álvarez-Dardet

J Epidemiol Community Health 2009;63;278-280

doi:10.1136/jech.2008.082347

Updated information and services can be found at:

http://jech.bmj.com/cgi/content/full/63/4/278

These include:

References This article cites 20 articles, 5 of which can be accessed free at:

http://jech.bmj.com/cgi/content/full/63/4/278\#BIBL

Rapid responses You can respond to this article at:

http://jech.bmj.com/cgi/eletter-submit/63/4/278

Email alerting Receive free email alerts when new articles cite this article - sign up in the box at service the top right corner of the article

Notes

To order reprints of this article go to:

http://journals.bmj.com/cgi/reprintform

To subscribe to Journal of Epidemiology and Community Health go to:

http:/journals.bmj.com/subscriptions/ 


\title{
How political epidemiology research can address why the millennium development goals have not been achieved: developing a research agenda
}

\author{
D Gil-González, ${ }^{1,2}$ M T Ruiz-Cantero, ${ }^{1,2,3}$ C Álvarez-Dardet ${ }^{1,2,3}$
}

\begin{abstract}
${ }^{1}$ Preventive Medicine and Public Health Area, University of Alicante, Alicante, Spain; ${ }^{2}$ Observatory of Public Policies and Health, University of Alicante, Alicante, Spain; ${ }^{3}$ CIBERESP, University of Alicante, Alicante, Spain

Correspondence to: Dr D Gil-González, Área de Medicina, Preventiva y Salud Pública, Universidad de Alicante, Campus San Vicente del Raspeig, Ap. 99, 03080

\section{ABSTRACT}

The Millennium Development Goals (MDG) progress targets have not been met. Nevertheless, the United Nations (UN) has not yet undertaken in-depth review in order to discover the reasons behind this lack of progress in achieving the MDG. From a political epidemiology perspective, the intention here is to identify the political elements affecting the social factors impeding MDG fulfilment and, at the same time, to suggest future public policies and appropriate proposals that are both more coherent and supported by broader, empirical knowledge of the relevant issues.
\end{abstract} Alicante,Spain; diana.gil@ua.es

Accepted 18 December 2008
The 8 Millennium Development Goals (MDG) and 18 Millennium Targets (MT), with their respective technical indicators for measuring progress, aim to influence the international political agenda in order to achieve minimum levels of well-being and health worldwide by the year 2015. ${ }^{1}$ Those MDG dealing directly with reducing infant mortality, improving nutrition and maternal health and the fight against infectious diseases are influenced by all the other goals, such as the eradication of poverty, universal access to education, gender equality, environmental sustainability and global partnership for development. In spite of initial political support and the fact that this is an agreement aimed at achieving minimum standards, halfway through the proposed timescale, the expected progress has not been achieved. ${ }^{23}$ Given this context, the construction of a Political Epidemiology Research Agenda ${ }^{4}$ could contribute towards a more objective approach to the situation, identifying those factors that are hindering MDG achievement while at the same time providing future policies and proposals with greater coherence and supported by a broader, empirical knowledge base.

Epidemiology has contributed to research on MDG through a description of health problems, and has also identified and analysed some of their causes and other barriers hindering MT achievement. ${ }^{5}$ It has also revealed methodological problems involved in measuring MDG progress, and in the evaluation of interventions carried out to this end. ${ }^{6}$ Concerned as it is with the study of all factors above populations (epi-demos-logos), epidemiology not only deals with individuals; social epidemiology, for example, also highlights social factors affecting health, such as poverty. ${ }^{7}$ Therefore, it is hoped that research results will raise awareness among decision-makers and their constituencies as regards the need to take social issues into account. From a political epidemiology perspective, the intention is to go even further, and to identify the political elements affecting the social factors that are impeding MDG fulfilment. This can be achieved simply by applying epidemiological methodology to the study of the effect that decisions (or lack of decisions) made by the institutions representing political power have on a population's health. ${ }^{89}$

Public policies, and their relation to health, are still not part of mainstream epidemiology, which continues to consider health as apolitical, and applies a definition of health that is centred on the individual illness rather than on society health problems. ${ }^{10}$ As a result, health policies are equated to healthcare services policies, and inequalities in health distribution are considered to be the result of individual problems (chosen lifestyle) or of how healthcare is implemented. This perspective has the effect of directing political attention towards the most manageable variable, the healthcare services. However, health inequalities have a political basis. ${ }^{10}$ Information on health inequality is not sufficient in order to decide what is inevitable and what is unjust, and such a decision does not depend solely on logic and empirical research, but also on an assessment of politics and ideology.

\section{TACKLING THE MULTIDIMENSIONAL PROBLEMS OF MDG}

Research carried out into the MDG has revealed the poor quality of health statistics in many countries and the problems associated with epidemiological monitoring systems. ${ }^{11}$ Many of the MT achievement measurement indicators suggested by the United Nations (UN) are considered to be unsatisfactory, and at least half lack the focus required in order to target public health interventions. ${ }^{12} 13$ The construction of new indicators, as an alternative to those proposed by the UN, is therefore considered necessary in order to provide a more accurate measurement of health achievements within the MDG framework. ${ }^{14}$

The failure to adapt information sources to the epidemiological transition of many countries constitutes a barrier to the implementation of effective policies $^{1215}$ as such policies require population health information compiled by independent, objective organisations. ${ }^{16}$ Another valuable resource for policy-making is the synthesis of scientific evidence, using systematic revision and meta-analyses in order to identify available knowledge, areas where information is lacking and research bias. ${ }^{17}$ Furthermore, systematic reviews of the literature related to MDG have identified an 
Box 1 Examples of problems hindering achievement of the millennium development goals and how a political epidemiology research approach could address these issues

\section{Problems}

- MT1, The eradication of poverty has not been achieved.

- Bad practice and bias in health statistics related to MDGs on a national and international scale, and little measurement of these indicators.

\section{Political epidemiology}

- Identification and analysis of political factors, such as government consumption, that may be hindering the eradication of poverty (MT1).

- Focus on priority indicators to encourage better primary data collection, develop better analytical methods and create audit trails.

\section{Box 2 Proposals for research aimed at enabling MDG achievement, from a political epidemiology perspective}

\section{Hypothesis and research areas}

- Identify MDG coherence, interaction and interdependence.

- Carry out research to identify the political elements contained within social factors impeding the achievement of MDG.

- Raise and deal with research issues relating to aspects that have not yet been analysed or have been insufficiently investigated with respect to MDG: (1) barriers existing in countries experiencing war, political repression or structural violence; (2) population displacement or forced migration; (3) the human rights situation; (4) environmental policies; (5) the influence of multinational companies on national economies; (6) the effects of decisions made by pharmaceutical companies on the prognosis for certain diseases, among other issues.

- Generate strategies for translating scientific knowledge into praxis (evidence frameworks) in order to contribute towards the effectiveness of policies aimed at achieving MDG.

- Propose hypotheses and analyse international and national public policies, whether health related or not, whose field of action is aimed at the MDG; locate the political levers that cause certain events or effects to have an influence on others.

- Identify areas of vulnerability at points of entry to action through establishing strength and transparency in the management and structure of institutions responsible to the political powers.

- Analyse how the lack of policies (a policy vacuum) can indicate underlying tendencies and reveal a lack of commitment to resolving population health problems.

\section{Research methodology}

- Develop tools to describe health problems and identify and analyse the causes of those problems that are impeding the achievement of targets.

- Identify and resolve methodological problems related to MDG progress measures and assessment of interventions carried out to this end.

- Identify the problems experienced by epidemiological monitoring systems and the poor quality of health statistics and indicators in some countries.

- Construct new indicators as an alternative to those proposed by the UN, with the aim of providing a more precise measurement of achievements in health within the MDG framework.

- Apply an epidemiological design responsive to those hypotheses incorporating international or national macro-structural factors that could constitute barriers to progress towards the MDG: ecological research (the existing population comprises the totality of countries within the world order), systematic review and meta-analysis.

\section{Social participation and ethics in research}

- Prioritise those countries that will be most disadvantaged by lack of progress towards MDG in political decision-making processes.

- Work together with those social and political actors who have demonstrated their willingness to direct their actions towards a common global strategy.

association between level of MDG progress and economic factors such as government spending, external markets, foreign aid and other economic policies. ${ }^{18}$ Translating these kinds of results into practice presents various problems. Therefore, the design of strategies for converting research results into effective intervention, and thus generating what are known as evidence frameworks, is a crucial task that would contribute towards the effectiveness of policies aimed at fulfilling the MDG. ${ }^{19}$

Research into the influence exerted by factors of a political nature, such as democratic freedom, on population health ${ }^{20}$ reveals the importance of analysing these factors through the use of ecological rather than individual bases, as individuals may not be aware that they are constrained by certain macro-structural models. Although each country's social and political history reflects unique and specific contexts in which political factors may not have had the same effect, this type of research is nevertheless an appropriate approach to the MDG, given that the research population is the totality of countries in the world order. The use of ecological designs has revealed how reductions in governmental spending in some countries have impeded the achievement of 
MDG related to the eradication of poverty. ${ }^{21}$ These results are confirmed by research carried out from a public health perspective, which reiterates the importance of recognising that poverty is a social construction and the historical product of political decisions implemented by institutions, and not a situation that arises "naturally" or inevitably (Box 1). ${ }^{22}$

\section{TOWARDS A NEW RESEARCH HYPOTHESIS ON MDG FROM A POLITICAL EPIDEMIOLOGY PERSPECTIVE}

The possible cause-effect relationships existing between politics and health should form the basis of MDG research hypotheses, given that international and national public policies aimed at MDG sectors, whether specifically health related or not, may have a significant influence on health and therefore represent a potential research subject for political epidemiology. ${ }^{23}$ The aim would be to identify how state and international organisation policies, whether designed and implemented within a purely health context or not, influence population health. Political epidemiology also needs to identify factors becoming policy levers, with certain events and effects influencing others. It must also identify areas of vulnerability at entry points to action, by establishing strength and transparency in the management and structure of institutions.

Research has shown that the structural adjustment policies imposed by the World Bank and the International Monetary Fund in the 1980s had a negative effect on social and health indicators such as infant mortality ${ }^{24}$ and poverty ${ }^{21}$ in Latin America and the Caribbean. It is possible that the so-called Washington consensus has had a more far-reaching effect, affecting other MDG. At state level, the decision taken by governments of developed countries in recent years to decrease the flow of development aid ${ }^{2}$ could be a factor that is impeding the achievement of MDG, another hypothesis meriting epidemiological research. A further possibility is that the influence of one institution representing the political powers could interact with the influence of another. For example, the highest levels of femicide in the world are to be found in those countries with low levels of government spending and whose political parties still do not permit parity for women in their national parliaments. ${ }^{25}$ Lastly, the absence of policies (a policy vacuum) affecting health now or in the future, even in areas not strictly related to the health sector or defined as being health related by their main actors, should also be the subject of research. A policy vacuum frequently indicates an underlying tendency with an influence on health, for example a lack of commitment to resolving population health problems, as in the case of avoidable maternal mortality rates. ${ }^{17}{ }^{26}$ In an attempt to address this issue, the World Health Organization's Commission on Social Determinants of Health (CSDH) of 2007 has outlined a model of health determinants, linked in turn to social structure and hierarchy, which could help to identify the different entry points for research and policies (Box 2). ${ }^{27}$

More than 150 years after Rudolf Virchow asserted the idea that "Medicine is a social science, and politics nothing but medicine at a larger scale", we find ourselves in the situation where the UN is trying to apply the second half of Virchow's idea when the scientific knowledge that would derive from the application of the first half is still non-existent. The MDG can be seen as an attempt to transform politics into medicine on a social scale; in this case, the UN is applying a model comprising much wishful thinking, opinions and good intentions that is limited by the lack of a solid scientific base, given the dearth of scientific information concerning the health implications of political initiatives. In order for Virchow's dream to become a reality, political epidemiological research is a necessity.

Competing interests: None.

\section{REFERENCES}

1. United Nations (UN) General Assembly. United Nations millennium declaration 2000. http://www.un.org/millennium/declaration/ares552e.htm laccessed 23 Jan 2009).

2. United Nations (UN). Millennium Development Goals. Report 2008. http://www.un. org/millenniumgoals/pdf/TheMillenniumDevelopmentGoalsReport2008.pdf laccessed 23 Jan 2009).

3. Sachs JD, McArthur JW. The Millennium Project: a plan for meeting the Millennium Development Goals. Lancet 2005;365:347-53.

4. Lumbreras B, Hernández Aguado I. Sharing hypotheses and ideas in public health research: contributing to the research agenda. J Epidemiol Community Health 2007:61:2-4

5. Morris JN. Uses of epidemiology. Int J Epidemiol 2007;36:1165-72.

6. MacCann MF. The Millennium Development Goals. A challenge to epidemiologists. Epidemiology 2007;18:653-7.

7. Krieger N. Why epidemiologists cannot afford to ignore poverty. Epidemiology 2007;18:658-63.

8. Porta M, ed. A dictionary of epidemiology, 5th edn. Oxford: International Epidemiological Association and Oxford University Press, 2008.

9. Gil-González D, Palma Solís M, Ruiz-Cantero MT, et al. The challenge to public health of the Millennium Development Goals: an approach from political epidemiology. Gac Sanit 2006;20(Suppl 3):61-5.

10. Bambra C, Fox D, Scott-Samuel AL. Towards politics of health. Health Promot Int 2005;20:187-93.

11. Boerma JT, Stansfield SK. Health statistics now: are we making the right investments? Lancet 2007;369:779-86.

12. Murray CJL. Towards good practice for health statistics: lessons from the Millennium Development Goal health indicators. Lancet 2007;369:862-73.

13. Attaran A. An immeasurable crisis? A criticism of the Millennium Development Goals and why they cannot be measured. PloS Med 2005;2:e318. http://medicine. plosjournals.org/archive/1549-1676/2/10/pdf/10.1371 journal.pmed.0020318-L.pdf (accessed 28 Sept 2008).

14. Eslava-Schmalbach J, Alfonso $\mathrm{H}$, Oliveros $\mathrm{H}$, et al. A new inequity-in-health index based on Millennium Development Goals: methodology and validation. J Clin Epidemiol 2008;61:142-50.

15. Walker $\mathbf{N}$, Bryce J, Black RE. Interpreting health statistics for policymaking: the story behind the headlines. Lancet 2007;369:956-63.

16. Abouzahr C, Adjei S, Kanchanachitra C. From data to policy: good practices and cautionary tales. Lancet 2007;369:1039-46.

17. Gil-González D, Carrasco-Portiño M, Ruiz MT. Knowledge gaps in scientific literature on maternal mortality: a systematic review. Bull World Health Organ 2006;84:903-9.

18. Palma Solís M, Hernández Aguado I, Gil-González D, et al. Factores económicos relacionados con los Objetivos de Desarrollo del Milenio de Salud: una revisión sistemática. Rev Panam Salud Pública 2008. Accepted.

19. Tugwell P, Robinson V, Grimshaw J, et al. Systematic reviews and knowledge translation. Bull World Health Organ 2006;84:643-51.

20. Franco A, Álvarez-Dardet C, Ruiz MT. Effect of democracy on health: ecological study. BMJ 2004;329:1421-3.

21. Palma Solís M, Gil-González D, Álvarez-Dardet C, et al. Political and social context of not attaining the Millennium Development Goal to reduce poverty. Bull World Health Organ 2008;86:772-9.

22. Schrecker T. Denaturalizing scarcity: a strategy of enquiry for public health ethics. Bull World Health Organ 2008;86:600-8.

23. Muntaner C, Chung H. Commentary: Macrosocial determinants, epidemiology, and health policy: should politics and economics be banned from social determinants of health research? J Public Health Policy 2008;29:299-306.

24. Palma-Solís M, Alvarez-Dardet C, Perez-Hoyos S, et al. State downsizing as a determinant of infant mortality and achievement of Millennium Development Goal 4. Int J Health Serv 2008;39. In press.

25. Palma-Solís M, Vives-Cases C, Álvarez-Dardet C. Gender progress and government expenditure as determinants of femicide. Ann Epidemiol 2008;18:322-9.

26. Cantero MT, Carrasco-Portiño M, Fiallos EE, et al. The myopia of governments contributes to maternal mortality: dying from socioeconomic and physical distances. J Epidemiol Community Health 2007:61:370-1.

27. World Health Organization (WHO). Commission of Social Determinants of Health A conceptual framework for action on social determinants of health. 2007. http:// www.who.int/social_determinants/resources/csdh_framework_action_05_07.pdf (accessed 18 Jan 2009). 